\title{
Practical study on heat pump enhancement by the solar energy
}

\author{
Omar Abdulhadi Mustafa Almohammed ${ }^{1,2}$, Farida Mizkhatovna Philippova ${ }^{1, *}$, Fouad Ibrahim Alhajj Hassan ${ }^{1}$, Nail \\ Farilovich Timerbaev ${ }^{1}$, and Anatoliy Anatolyevich Fomin ${ }^{3}$ \\ ${ }^{1}$ Department of Electrical Engineering, Kazan State Power Engineering University, Kazan, Russia \\ ${ }^{2}$ Technical College Of Mosul, Northern Technical University, Mosul, Iraq \\ ${ }^{3}$ Institute of mechanical engineering and road transport, Vladimir State University, Vladimir, Russia
}

\begin{abstract}
The heat pumps system is one of the most remarkable system that is widely used around the world, their capacity is different according to necessity. The energy consumption in those systems will limit their effectiveness. This study will try to prove the positive reactance of the new changes (the additional heat exchanger) on the heat pump work, where the power consumption will reduce about (13-17\%). The study includes the experimental results of the laboratory model, which has been manufactured in the laboratories of the technical college of Mosul/ Northern technical university-Iraq. The model consists of the heat pump that was improved by using the additional heat exchanger, its duty is to heat the refrigerant before entering the compressor, by using solar energy. The results of this work prove the positive effect of the additional heat exchanger, on the coefficient of performance of the heat pump, in both modes of heating and cooling. The conclusions are useful to the industries that deal with heat pumps.
\end{abstract}

\section{Introduction}

One of the most popular systems in human life application is the "Heat pump". Heat pumps are one of the most effective systems that produce or remove thermal energy[1].

The higher activity of the thermal cycle of that system leads to wide usage around the world. In recent years, many companies and foundations tried to improve the heat pumps to offer the combined system in which renewable energy is used [2]. The solar energy is the most common type which is directly used to increase the coefficient of performance of the heat pumps especially in cold climate [3]. In most situations, solar energy was used to heat the evaporator of the system to prevent its freezing, as well as to avoid the wet refrigerant entering the compressor. The thermal cycle of the heat pump starts from the compression process where mechanical energy is used for refrigerant pumping. The next process is the heat rejection from the condenser where the refrigerant changes its phase from gas to liquid state. This part of the system is widely used in domestic heating systems [4]. The refrigerant is released to the evaporator at low pressure through the expansion device. The evaporation process will happen under low temperatures. To make the system works properly, the evaporator temperature must be kept at the permissible limit, therefore, the necessity to use solar energy will appear [2].

In the present work, the additional heat exchanger after the evaporator will heat the refrigerant before entering the compressor as shown in figure (1). This change is very simple and maybe easily added to any heat pump.

\section{The experimental apparatus}

The project as shown in figure (1) and figure (2) consists of the two thermal systems working together. The first is the classic heat pump including the following components: the sealed compressor (1) having the power of $150 \mathrm{w}$, the refrigerant condenser (2), the expansion device (3), the evaporator (4), and the additional heat exchanger (14) that heats the refrigerant entering the compressor. The second thermal system may also be called an open cycle heat pump that equalizes the thermal effect of the first system, where it absorbs the heat from the condenser of the classic heat pump by evaporating the water and heating the evaporator by condensing the water vapor. These processes are to keep both systems working continuity and produce the distilled water, which can be directed for different usage.

\footnotetext{
* Corresponding author: filippova.fm@kgeu.ru
} 


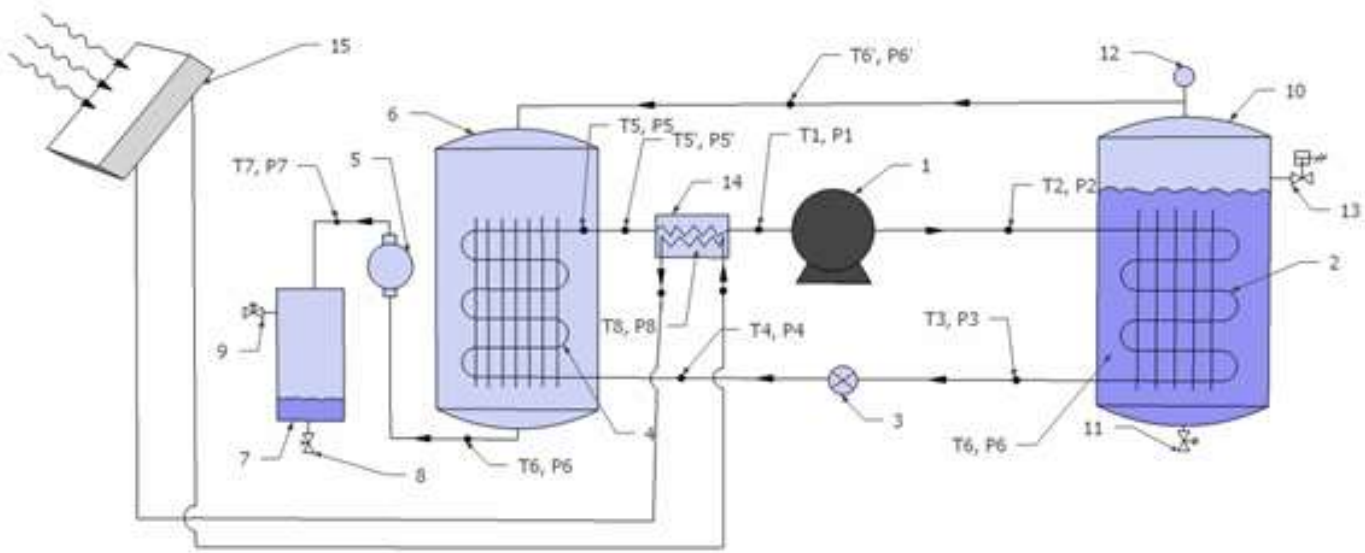

Fig. 1. The improved heat pump system.

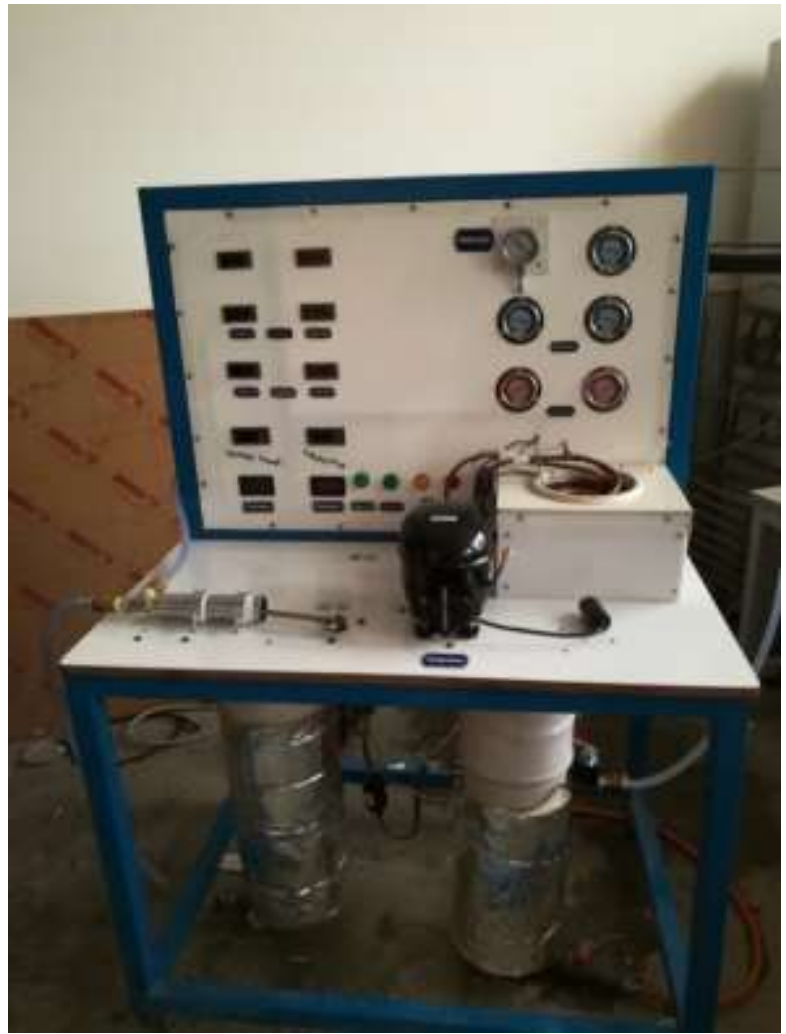

Fig. 2. The real experimental system.

\section{Thermal analysis}

The heat pump can be defined as the system that carries the heat from a place that may be colder than that place receiving that energy [6], [7], and [8]. The classic heat pump consists of four components: the compressor, the refrigerant condenser, the expansion device, and the refrigerant evaporator [9].

In typical cases, the refrigerant enters the compressor as a saturated vapor. In this paper, the additional heat exchanger added to heat the refrigerant entering the compressor. The aim of this change is to ensure that the dry refrigerant will enter the compressor, therefore, the compressor still works for a long time. The other purpose of that improvement is to reduce the power consumption by the system, because the increment in the pressure of the refrigerant, caused by the increment in its temperature, will decrease the pressure difference across the compressor.

There are many types of refrigerants used in heat pumps. The Freon (R-134a) used in the present model. It is selected because of its several advantages [10]. It is nonflammable, cheap, non-toxic, available everywhere, has no effect on the atmosphere [11], etc. The following figure shows the representation of this system on the (Ph) diagram.

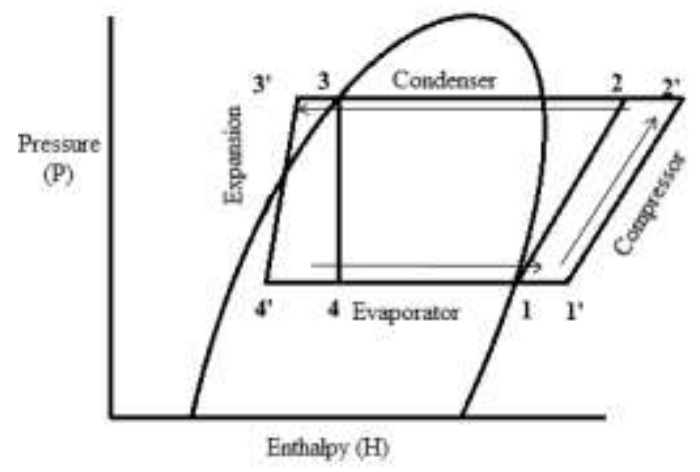

Fig. 3. The Mollier diagram.

The working of this system begins at the compression process. The compressor forces the refrigerant into the condenser by increasing its pressure from point (1') to point (2'). The line between (1) and (2) is the compression process in the typical situation when the refrigerant enters the compressor at a saturated vapor status. The power consumption by the compressor can be determined by the following formula: 
Table 1.

\begin{tabular}{|c|c|c|c|c|c|c|c|c|c|c|c|c|}
\hline $\mathrm{P}_{\mathrm{C}, \mathrm{i},}$ & $\mathrm{P}_{\mathrm{C}, \mathrm{o}}$ & $\mathrm{P}_{\mathrm{E}, \mathrm{i},}$ & $\mathrm{P}_{\mathrm{E}, \mathrm{o},}$ & $\mathrm{P}_{\mathrm{HX}, \mathrm{o},}$ & $\mathrm{t}_{\mathrm{C}, \mathrm{i}}$ & $\mathrm{tC}_{\mathrm{C}, \mathrm{o}}$ & $\mathrm{t}_{\mathrm{E}, \mathrm{i}}$ & $\mathrm{t}_{\mathrm{E}, \mathrm{o}}$ & $\mathrm{t}_{\mathrm{HX}, \mathrm{i}}$ & $\mathrm{t}_{\mathrm{HX}, \mathrm{o}}$ & $\mathrm{t}_{\mathrm{w}}$ & $\mathrm{t}_{\text {Heater }}$ \\
\hline 0.63 & 0.62 & 0.034 & 0.034 & 0.041 & 28.8 & 21 & 3.8 & 0.3 & 6.6 & 25.8 & 24 & 34 \\
\hline 0.6757 & 0.66 & 0.027 & 0.027 & 0.034 & 30.8 & 21.2 & 4.1 & 0.3 & 6.3 & 26 & 25 & 35 \\
\hline 0.70 & 0.69 & 0.069 & 0.069 & 0.062 & 34.1 & 23.6 & 2.9 & 0.3 & 7.3 & 29.6 & 28 & 41 \\
\hline 0.765 & 0.744 & 0.069 & 0.069 & 0.069 & 38.1 & 24.7 & 3.4 & 1.1 & 7.6 & 32.1 & 30 & 47 \\
\hline 0.8 & 0.77 & 0.062 & 0.069 & 0.069 & 38.8 & 25.5 & 3.8 & -0.1 & 7.7 & 31.6 & 31 & 45 \\
\hline
\end{tabular}

$$
P_{c}=\dot{m}\left(h_{2^{\prime}}-h_{1^{\prime}}\right)
$$

where $\mathrm{P}_{\mathrm{c}}$ - is the power consumed by the compressor $(\mathrm{kJ} / \mathrm{kg})$,

$\dot{\mathrm{m}}$ - is the mass flow rate of the refrigerant $(\mathrm{kg} / \mathrm{s})$,

$\mathrm{h}_{1}{ }^{\prime}$ - is the enthalpy of refrigerant before compression $(\mathrm{kJ} / \mathrm{kg})$,

$\mathrm{h}_{2}{ }^{\prime}$ - is the refrigerant enthalpy at the entrance of the condenser $(\mathrm{kJ} / \mathrm{kg})$.

The refrigerant temperature will increase as its pressure increases because the relationship between pressure and temperature is direct [12]. Therefore; the condenser works to reject the heat from the refrigerant at constant pressure to condensate it to a liquid state. The heat rejection by the condenser is estimated by the following formula:

$$
Q_{c}=\dot{m}\left(h_{2^{\prime}}-h_{3^{\prime}}\right),
$$

where $Q_{\mathrm{c}}$ - is the heat rejected by the condenser $(\mathrm{kW})$;

$h_{3}{ }^{\prime}-$ is the liquid refrigerant enthalpy before entering the expansion device $(\mathrm{kJ} / \mathrm{kg})$.

The points (1,2,3 and 4) represent the typical system where the refrigerant enters the compressor at the saturated vapor state and exit the condenser in a saturated liquid state [13]. Due to low pressure in the raw water vessel, the water inside it is maintained at lower temperatures as it will change into vapor state as soon as the temperature raises. The cold water leads to sub-cooling the refrigerant at the end of the condensation process. The thermal energy of the solar collector was used to heat the refrigerant entering the compressor, to decrease the power consumption of the system, where the coefficient of performance of the system increased on both thermal sides. The refrigerant leaves the evaporator at saturated vapor status to enter the additional heat exchanger. The heat added by the heat exchanger is calculated by the formula (3):

$$
Q_{H X}=\dot{m}\left(h_{1^{\prime}}-h_{1}\right),
$$

where $\mathrm{Q}_{\mathrm{HX}}$ - the heat added by the heat exchanger $(\mathrm{kW})$;

$\mathrm{h}_{1}$ - is the refrigerant enthalpy before entering the heat exchanger $(\mathrm{kJ} / \mathrm{kg})$.

The additional heat exchanger works to superheat the refrigerant because the compressors are designed to deal with gases only [14].

The formula (4) is the amount of heat absorbed by the evaporator when the refrigerant leaves the evaporator at the saturated vapor state. In fact, the refrigerant exiting from the evaporator will be in the super-heat state because is very difficult to control the refrigerant state at saturation, and the gas entering the compressor must be dry to avoid the inconvenience in the compressor.

$$
Q_{e}=\dot{m}\left(h_{1}-h_{4^{\prime}}\right) \text {, }
$$

where $\mathrm{Q}_{\mathrm{e}}-$ is the heat absorbed by the evaporator $(\mathrm{kJ} / \mathrm{kg})$;

$\mathrm{h}_{4}{ }^{\prime}$ - is the enthalpy of the refrigerant at the evaporator entrance $(\mathrm{kW})$.

The coefficient of performance, of cooling CCOP of the heat pump, is a measure of the heat absorbed by the evaporator of the heat pump via the power consumption in the compressor [15]. It can be illustrated as in the following:

$$
\begin{aligned}
& \text { CCOP }=\frac{\text { cooling effect }}{\text { work of the compressor }} \\
& \text { CCOP }=\frac{h_{1}-h_{4^{\prime}}}{h_{2^{\prime}}-h_{1^{\prime}}},
\end{aligned}
$$

The heat pumps may be used for heating, in this case. Here, the heating coefficient of performance (HCOP) represented as:

$$
\begin{aligned}
& H C O P=\frac{\text { heating effect }}{\text { work of the compressor }} \\
& H C O P=\frac{h_{2^{\prime}}-h_{3^{\prime}}}{h_{2^{\prime}}-h_{1^{\prime}}},
\end{aligned}
$$

The present work tries to make a comparison between the classic cycle (points 1,2,3 and 4) and the improved cycle (points 1', 2', 3', and 4') to show the effect of the additional heat exchanger on the system performance.

\section{Procedure and readings}

The real system in this study is manufactured in the technical college of Mosul - Northern technical university/ Iraq. The purpose of system manufacturing is to produce an economical system for water distillation. Several readings in different conditions were taken as in table 1.

The representation of the symbols in the table (1) and their units are shown in the following:

$\mathrm{P}_{\mathrm{C}, \mathrm{i}}$ - pressure of the refrigerant at the condenser entrance, Mpa;

$\mathrm{P}_{\mathrm{C}, \mathrm{o}}-$ pressure of the refrigerant at the condenser exit, Mpa; 
Table 2.

\begin{tabular}{|c|c|c|c|c|c|c|c|}
\hline $\mathrm{h}_{1}{ }^{\prime}$ & $\mathrm{h}_{2}{ }^{\prime}$ & $\mathrm{h}_{3}{ }^{\prime}$ & $\mathrm{h}_{4}{ }^{\prime}$ & $\mathrm{h} 1$ & $\mathrm{Pc} / \mathrm{Pe}$ & HCOP & CCOP \\
\hline 425 & 508 & 203 & 200 & 370 & 18.2 & 3.675 & 2.711 \\
\hline 426 & 520 & 205 & 197 & 365 & 24.5 & 3.351 & 2.436 \\
\hline 430 & 491 & 203 & 201 & 380 & 10.2 & 4.721 & 3.754 \\
\hline 432 & 498 & 204 & 201 & 380 & 11.1 & 4.455 & 3.500 \\
\hline 432 & 500 & 204 & 201 & 380 & 12.8 & 4.353 & 3.397 \\
\hline
\end{tabular}

$\mathrm{P}_{\mathrm{E}, \mathrm{i}}$ - pressure of the refrigerant at the evaporator inlet, Mpa;

$\mathrm{P}_{\mathrm{E}, \mathrm{i}}$ - pressure of the refrigerant at the evaporator outlet, Mpa;

$\mathrm{P}_{\mathrm{HX}, \mathrm{o}}$ - pressure of the refrigerant at the heat exchanger exit, Mpa;

$t_{C, i}$ and $t_{C, o}-$ are the temperature of the refrigerant at the condenser inlet and outlet respectively, ${ }^{\circ} \mathrm{C}$;

$t_{E, i}$ and $t_{E, o}$ - are the temperature of the refrigerant at the evaporator inlet and outlet respectively, ${ }^{\circ} \mathrm{C}$;

$t_{\mathrm{HX}, \mathrm{i}}$ and $\mathrm{t}_{\mathrm{HX}, \mathrm{o}}$ - are the temperature of the refrigerant at the heat exchanger inlet and outlet respectively, ${ }^{\circ} \mathrm{C}$;

$t_{w}-$ is the temperature of the water around the condenser, ${ }^{\circ} \mathrm{C}$;

$t_{\text {Heater }}-$ is the temperature water around the heat exchanger, ${ }^{\circ} \mathrm{C}$.

The enthalpy of the refrigerant at each point of the actual cycle is found from the pressure - enthalpy (P-h) diagram. The table (2) is showing the results of the improved system.

The representation of the symbols in the table (2) and their units are shown below:

h1', h2', h3', h4', and h1- are the enthalpies of the refrigerant in the different points in the cycle as illustrated in the figure $(3), \mathrm{kj} / \mathrm{kg}$;

$\mathrm{PC} / \mathrm{Pe}-$ is the relative pressure which is equal to the pressure inside the condenser divided by the pressure inside the evaporator;

HCOP - is the coefficient of performance of the heat pump in heating mode;

CCOP - is the coefficient of performance of the cycle in cooling mode.

The following table shows the high (condenser) and low (evaporator) pressures in both cycles.

Table 3.

\begin{tabular}{|c|c|}
\hline $\mathrm{P}_{\mathrm{C}}, \mathrm{Mpa}$ & $\mathrm{P}_{\mathrm{E}}, \mathrm{Mpa}$ \\
\hline 0.630 & 0.034 \\
\hline 0.676 & 0.027 \\
\hline 0.700 & 0.069 \\
\hline 0.765 & 0.069 \\
\hline 0.800 & 0.062 \\
\hline
\end{tabular}

The resultant enthalpies in the case of the typical cycle are shown in the following table:
Table 4. The resultant enthalpies in the case of the typical cycle.

\begin{tabular}{|c|c|c|c|c|c|}
\hline $\mathrm{h}_{1}$ & $\mathrm{~h}_{2}$ & $\mathrm{~h}_{3}=\mathrm{h}_{4}$ & $\mathrm{Pc} / \mathrm{Pe}$ & HCOP & CCOP \\
\hline 370 & 430 & 230 & 18.2 & 3.33 & 2.33 \\
\hline 365 & 435 & 232 & 24.5 & 2.9 & 1.9 \\
\hline 380 & 427 & 236 & 10.2 & 4.06 & 3.06 \\
\hline 380 & 430 & 241 & 11.1 & 3.78 & 2.78 \\
\hline 380 & 432 & 242 & 12.8 & 3.65 & 2.65 \\
\hline
\end{tabular}

The work of the heat pump depends on the pressure difference between the condenser and the evaporator. The relative pressure $(\mathrm{Pc} / \mathrm{Pe})$ is the dimensionless magnitude that governs the work of the heat pumps. The curves, in figure 4 below, illustrate the behavior of the coefficient of performance of the system, according to the relative pressure of the system.

The formula (7) resulted from the curve of the typical cycle, while formula (8) present the improved system.

$$
\begin{gathered}
H C O P=-0.001 R p^{3}+0.0565 R p^{2}- \\
-1.0412 R p+9.8745 \\
H C O P=0.0049 R p^{2}-0.2632 R p+6.858
\end{gathered}
$$

where $\mathrm{Rp}$ - is the relative pressure.

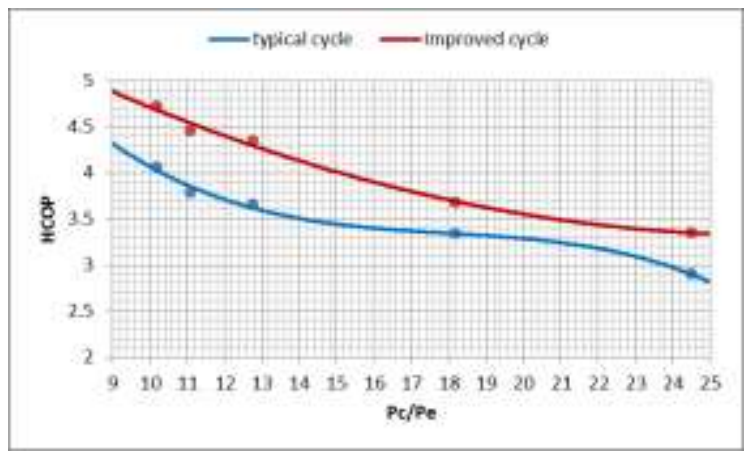

Fig. 4. The relationship between the relative pressure and the HCOP.

The differences in heating coefficient of performance between the typical and the improved cycle are clear, from the shape of the curves in figure (4) as well as the governing equations.

The heat pumps are used for heating and cooling, so that; the relation between the relative pressure and the coefficient of performance in the cooling mode included in this study is shown in figure (5). 


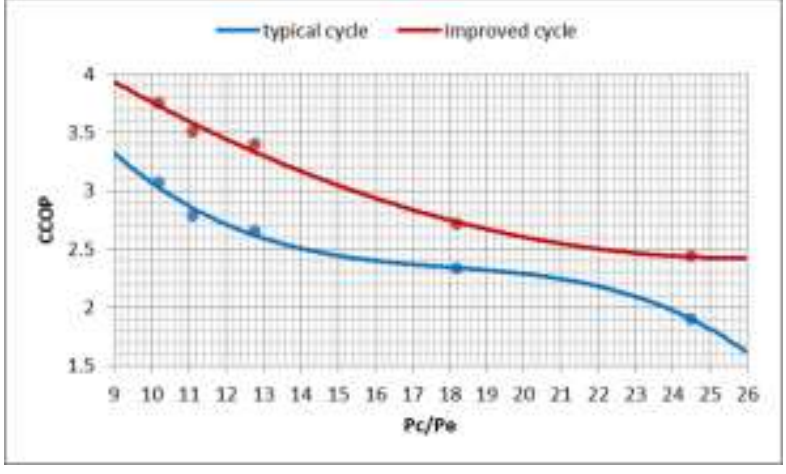

Fig. 5. The relationship between the relative pressure and the CCOP.

The following formulas (9) and (10) represent what to that get from the curves in figure (5) for both of typical and improved situation respectively.

$$
\begin{gathered}
C C O P=-0.001 R p^{3}+0.0565 R p^{2}- \\
-1.0412 R p+8.8745 \\
C C O P=0.0053 R p^{2}-0.2761 R p+5.9847
\end{gathered}
$$

\section{Conclusions}

1. The refrigerant heating before the compression process will increase the coefficient of performance in both heating and cooling situation.

2. The improvement of the heat pump by using solar energy will raise its performance, which leads to power consumption decrement.

3. The coefficient of performance of the heat pump is reversely proportionate with the relative pressure of the system.

\section{References}

1. H. Pieper, T. Ommen, B. Elmegaard, A. Volkova, W.B. Markussen, Optimal Design and Dispatch of Electrically Driven Heat Pumps and Chillers for a New Development Area, Environmental and Climate Technologies, 24 (3), 470-482 ( 2021)

2. T.D. Čož, A. Kitanovski, A. Poredoš, Exergoeconomic optimization of a district cooling network, Energy, 135, 342-351 (2017)

3. D. Carbonell, M.Y. Haller, E. Frank, Potential benefit of combining heat pumps with solar thermal for heating and domestic hot water preparation, Energy Procedia, 57, 656-2665 (2014)

4. T. Berntsson, Heat sources - Technology, economy and environment, International Journal of Refrigeration, 25 (4), 428-438 (2002)

5. S. Harrison, The Potential and Challenges of Solar Boosted Heat Pumps for Domestic Hot Water Heating, 12th IEA Heat Pump Conference (2017)
6. Ir.P. Pattijn, A. Baumans, Fifth-generation thermal grids and heat pumps, 12th IEA heat pump conference (2017)

7. K.J. Chua, S.K. Chou, W.M. Yang, Advances in heat pump systems: A review, Applied Energy, 87, 3611-3624 (2010)

8. Z. Cheng, W. Shi, B. Wang, Vapor injected heat pump using non-azeotropic mixture R32/R1234ze(E) for low temperature ambient, 12th IEA heat pump conference (2017)

9. Compact Heat Pumps, 12th International Heat Pump Conference, Rotterdam, The Netherlands (2017)

10. A.K. Das, R. Mohanty, Performance enhancement of domestic refrigeration system using r-134a refrigerant blended with graphene as nano additives, Lecture Notes in Mechanical Engineering, 99-110 (2021)

11. A.L. Tarish, J. Al Douri, V. Apostol, H.L. Pop, C. Ionita, Exergy and performance analyses of impact subcooling for vapor compression refrigeration system utilizing eco-friendly refrigerants, IOP Conference Series: Materials Science and Engineering, 997 (1), 012158 (2020)

12. L. Shao, X. Ma, X. Wei, Z. Hou, X. Meng, Design and experimental study of a small-sized organic Rankine cycle system under various cooling conditions, Energy (2017)

13. V. Gudjonsdottir, C.A. Infante Ferreira, Technical and economic analysis of wet compression resorption heat pumps, International Journal of Refrigeration, 117, 140-149 (2020)

14. V. Tufano, Heat recovery in distillation by means of absorption heat pumps and heat transformers, Applied Thermal Engineering, 17, 171-178 (1997)

15. O.A.M. Almohammed, N.F. Timerbaev, B.I. Ahmad, Heat Pump Application for Water Distillation, 2019 International Multi-Conference on Industrial Engineering and Modern Technologies (FarEastCon), Vladivostok, Russia, 1-5 (2019) DOI: 10.1109/FarEastCon.2019.8934168. 